\title{
Tonal association in neutral and subject-narrow-focus sentences in Brazilian Portuguese: a comparison with European Portuguese
}

\author{
FLAVIANE ROMANI FERNANDES
}

\begin{abstract}
This paper presents a comparative description and analysis of the intonational contours of Brazilian Portuguese (BP) sentences in neutral and subject-narrow-focus conditions. Making use of the literature on European Portuguese (EP) intonation, it also compares BP intonation with the intonation of EP sentences under the same conditions, looking for similarities and differences between the intonational patterns of these two Portuguese varieties. Our results indicate that BP neutral sentences can optionally show pitch accents associated with all prosodic words ( $\omega$ s). In subject-narrowfocus conditions, the same type of pitch accents that are found associated with non-focused subjects can also be found with focused subjects. In addition, it is also possible to find a phrasal accent associated with the right boundary of the phonological phrase ( $\phi)$ that contains the focused subject. In contrast to $B P$, in EP neutral sentences, pitch accents are associated with the I-initial and I-final ws. Furthermore, in this variety, in subject-narrow-focus conditions there is always a special bitonal pitch accent carried by the focused subject and there are no phrasal accents associated with boundaries of the $\phi$ that contains the subject.
\end{abstract}

\section{Introduction}

This paper consists in the comparative description and analysis of the tonal association of basic word order sentences in neutral and subject-narrow-focus conditions in Brazilian Portuguese (henceforth, BP), developed within the autosegmental metrical approach to intonational phonology. ${ }^{1}$ The aim is to

\footnotetext{
${ }^{1}$ We assume here that SV (subject and verb), SVO (subject, verb and object) and SVAdv (subject, verb and adverb) sentences display the basic word order pattern both in BP and in EP (cf. Silva, 2001; Costa \& Galves, 2002; Tavares Silva, 2004
} 
investigate if the kind of tonal association pattern displayed in BP subjectnarrow-focus sentences presents properties that distinguish it from the tonal association pattern displayed by BP neutral sentences. The paper also includes a comparison with the intonation of European Portuguese (henceforth, EP) sentences under the same conditions, looking for similarities and differences between the intonational patterns of these two Portuguese varieties.

Our study will be based on our own BP data and also on previous studies on the intonational structure of BP and EP done within the autosegmental metrical approach to intonational phonology (Cunha, 2000; Frota \& Vigário, 2000; Tenani, 2002, for BP; and Frota, 1991, 1993, 1997, 2000, 2002a, b, 2003; Grфnnum \& Viana, 1999; Vigário, 1998; Frota \& Vigário, 2000; for $\mathrm{EP})$.

According to this framework, there is a phonological organization in intonation that consists of a string, with local tonal events associated with local places in segmental structure (Beckman \& Pierrehumbert, 1986; Pierrehumbert \& Beckman, 1988; Ladd, 1996; among others). In languages like English, EP and BP, the important tonal events of the tonal string are the pitch accents and the edge-related tones. These two types of tonal events can be analyzed as pitch targets, high $(\mathrm{H})$ and low $(\mathrm{L})$. Between tonal events, the pitch contour is phonologically underspecified and can be described as formed by the transitions from one event to the other.

Pitch accents are associated with the stressed syllables of the segmental string, and can be simple (monotonal: $\mathrm{L}^{*}$ or $\mathrm{H}^{*}$ ) or complex (bitonal: $\mathrm{H}^{*}+\mathrm{L}$, $\mathrm{H}+\mathrm{L}^{*}, \mathrm{~L}^{*}+\mathrm{H}$ or $\left.\mathrm{L}+\mathrm{H}^{*}\right)$. The edge-related tones are associated with prosodic constituent boundaries, and they may be of two types: boundary tones or phrasal accents (respectively, $\mathrm{L} \%$ or $\mathrm{H} \%$ and $\mathrm{L}^{-}$or $\mathrm{H}^{-}$in Pierrehumbert's notation).

In the autosegmental metrical theory of intonational phonology, tonal events are structured according to constituent and prominence relationships defined in the prosodic structure. According to Hayes \& Lahiri (1991), Frota (2000), and Tenani (2002), the pertinent prosodic structure for intonation in languages such as Bengali, EP and BP, respectively, is captured by the Prosodic Hierarchy Theory (Selkirk, 1984; Nespor \& Vogel, 1986; and others). We will use the following prosodic domains in our description of BP tonal structure: the phonological word (or prosodic word $-\omega$ ), the phonological phrase $(\phi)$ and the intonational phrase $(\mathrm{I}){ }^{2}$

In section 2, we will present previous analyses of the intonational contour of BP and EP sentences with neutral and narrow-focus, as found in the literature. The methodology used in this paper will be presented in section 3 .

for BP; and Duarte, 1987; Âmbar, 1992; Martins, 1994; Costa, 1998; Costa \& Galves, 2002 for EP).

2 See Tenani (2002) and Frota (2000), for the formation of phonological and intonational phrases, in BP and EP, respectively, and Schwindt $(2000,2001)$ and Vigário (2003) for the phonological word in BP and EP, respectively. 
In section 4 , the results of our own analysis of the intonational contour of neutral and narrow-focus subject sentences in BP will be provided and compared to those found in previous works. Finally, we will conclude in section 5 with a comparison between the intonational structure of neutral and subject-narrow-focus sentences of BP and EP.

\section{Previous analyses of neutral and focus sentence intonation in Portuguese}

Previous research on BP intonation includes Rameh (1962), Fernandes (1976), Gebara (1976), Cagliari (1980, 1982), Reis (1984), Moraes (1990, 1998), Gonçalves (1997), Madureira (1999), Cunha (2000), Frota \& Vigário (2000) and Tenani (2002), among others. Among these, only Cunha (2000), Frota \& Vigário (2000) and Tenani (2002) address BP declarative sentence intonation within the framework of autosegmental metrical theory of intonational phonology. These three works deal with the intonation of BP declarative neutral sentences. Nevertheless, Frota \& Vigário (2000) also refer to the intonation of EP declarative neutral sentences, since the paper consists of a comparative analysis of the intonational structure of BP and EP neutral declarative sentences, among other phonological properties of these two varieties.

Cunha (2000), Frota \& Vigário (2000) and Tenani (2002) identify the $\mathrm{H}+\mathrm{L}^{*}$ bitonal pitch accent associated with the head of the last $\phi$ of I as the main property of the final contour of BP neutral declaratives. These same authors also assert that there can be an L\% boundary tone associated with the right boundary of $\mathrm{I}$, when the last posttonic syllable of $\mathrm{I}$ is pronounced.

For the non-final contour of BP neutral declaratives, Frota \& Vigário (2000) and Tenani (2002) find tonal events associated with $\phi s$, and they also claim that an additional $\mathrm{H}$ tone can be associated with a pretonic syllable that is non-adjacent to the stressed syllable of $\omega$ s composed of more than three pretonic syllables. Frota \& Vigário (2000) suggest that this pattern is reminiscent of the intonational properties of languages like Japanese and Korean, where some tonal events crucially depend on the quantity of moras or syllables (Pierrehumbert \& Beckman, 1988; Jun, 1996). Tenani (2002) hypothesizes that this same additional $\mathrm{H}$ tone can be associated with the pretonic syllable that carries secondary stress. She further notes that phrasal accents are not associated with $\phi$-edges, and that there is a preferential alternance of the type L H L H between tones in BP neutral declaratives, a pattern also proposed to characterize BP in Frota \& Vigário (2000).

To the best of our knowledge, no study of the intonational structure of BP narrow-focus sentences has been previously conducted within the autosegmental metrical theory of intonational phonology, and Gonçalves (1997) is the only work known to us which specificaly deals with narrowfocus sentence intonation in this variety of Portuguese. We should add, 
however, that Cagliari (1982) also describes BP narrow-focus sentences ('emphatic assertions', in his terms). He claims that emphatic assertions are composed of a tone 5 (according to his notation) forming a convex curve or a 'hill' with abrupt slopes, followed by a declining contour until the end of the sentence.

Gonçalves (1997) describes the intonational pattern of neutral sentences, before presenting the intonational pattern of sentences with narrow-focus constituents in BP. According to this author, neutral sentences present a descendent pattern formed of a rising onset and a falling nucleus. This pattern is represented in (1), in Gonçalves's formalization:

\section{(1) PNEB}

(Non-Emphatic Basic Pattern)

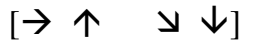

(Onset) (Nucleus)

For the focus sentences, Gonçalves (1997) proposes that the representative prosodic pattern of the focused elements is better displayed as in (2), where ' $s$ ' stands for the syllable; ' $S$ ' represents the syllable bearing lexical stress; '(s)' corresponds to an optional syllable; ' $₫$ ' indicates that the melodic curve is falling in the syllable that bears the emphatic stress, which may coincide with the lexical stress or not; and $\phi$ represents the phonological phrase.

$$
\begin{aligned}
& \begin{array}{llll}
\mathrm{s} & \mathrm{s} & \mathrm{S} & \text { (s) }
\end{array} \\
& {\left[\begin{array}{llll}
\uparrow & \searrow & \searrow & \downarrow
\end{array}\right] \phi}
\end{aligned}
$$

For Gonçalves, the prosodic domain of BP focused elements is the phonological phrase, according to the $\phi$-algorithm proposed by Nespor \& Vogel (1986). Furthermore, this intonational pattern is argued to specifically characterize the focused element, instead of affecting the whole sentence.

In contrast with BP, studies of EP intonation within the autosegmental metrical theory of intonational phonology date back to the eighties (Viana, 1987; Frota, 1991, 1997, 2000, 2002a, b, 2003; Falé, 1995; Vigário, 1998; Grфnnum \& Viana, 1999; Frota \& Vigário, 2000; among others). All these works report an initial rising, an intermediary plateau and a pronounced final fall as the global aspect of the EP neutral declarative contour, as earlier noted by Delgado Martins \& Lacerda (1977). However, these works differ with respect to the analysis of the types of tones associated with the intonational contour.

Viana (1987) argues for an $\mathrm{H}^{*} \mathrm{~L}$ tonal sequence associated with the last stressed syllable of the EP intonational contour. On the other hand, Frota (1993, 1997, 2000, 2002a, b), Falé (1995), Vigário (1998) and Frota \& Vigário (2000) claim that the final neutral declarative contour is better modeled by an $\mathrm{H}+\mathrm{L}^{*}$ bitonal pitch accent, followed by an $\mathrm{L} \%$ boundary tone associated with the final I-edge. Gronnum \& Viana (1999) analyze the final 
fall of EP neutral sentences as including an $\mathrm{L}^{*}$ pitch accent preceded by an inicial $\mathrm{H}^{*}$ target.

Frota (2003) proposes that the tones associated with the EP initial contour are of two different types, according to their phonological status: they are either pitch accents (Frota 1997, 2000, 2003; Vigário, 1998; Grфnnum \& Viana, 1999) or edge-related tones (Frota, 1993, 2000, 2003; Vigário, 1998). Whereas pitch accents are consistently aligned with stressed syllables, edgerelated tones vary with respect to syllable alignment and they are associated with prosodic phrase boundaries. The latter tonal type is associated with the beginning of I.

The initial pitch accent present in EP may have three different forms: the $H^{*}$ pitch accent (Frota 1997, 2000, 2003; Vigário, 1998; Grфnnum \& Viana, 1999); the $\mathrm{H}+\mathrm{L}^{*}$ bitonal pitch accent (Frota, 2003); and the $\mathrm{L}^{*}+\mathrm{H}$ bitonal pitch accent (Frota, 1993, 2000, 2003; Vigário, 1998). The edge-related tone associated with the beginning of $\mathrm{I}$ is represented as an $\mathrm{H}$ in works on EP intonation (Frota, 1993, 2000, 2003; Vigário, 1998).

Studies on EP narrow-focus intonation are fewer than those on neutral intonation (see in particular, Frota, 1997, 2000, 2002a, b; Vigário, 1998). According to these two authors, the focused element always carries an $\mathrm{H}^{*}+\mathrm{L}$ bitonal pitch accent, where the $\mathrm{H}$ is aligned with the stressed syllable and the $\mathrm{L}$ is aligned with the immediate following syllable.

Both Frota and Vigário report that after the final fall of the narrow-focus contour two things may happen: (i) an $\mathrm{H}+\mathrm{L}^{*}$ bitonal pitch accent is associated with the head of the last $\phi$ of I, and followed by an L\% boundary tone which is associated with the final I-edge, in which case the $F_{0}$ level of the pitch accent is substantially lowered; or (ii) only an L\% boundary tone is associated with the final I-edge.

In next sections, we will present our results of the comparative description and analysis of the tonal association of BP neutral and narrow-focus subject sentence contours. Taking into account different factors (see 3.1.), we will evaluate if our results for BP neutral sentences confirm those described earlier in the intonational literature of BP neutral sentences. In addition, we will compare our description of BP sentences in neutral and narrow-focus subject conditions with descriptions of EP sentences, under the same conditions, found in the literature.

\section{Methods}

\subsection{Material speech}

Our corpus consists of single clause sentences. Aside from vowels, the words chosen are largely formed of sonorant or at least voiced consonants. Examples: alunas /a'lunas/ 'students (fem)'; jovens /'zovẽjs/ 'teenagers'; belas /'belas/ 'beautiful (fem)'. The sentences systematically vary in number of syllables and in the number of $\omega$ s that compose the subjects and predicates. In 
addition, the distance is variable between the stressed syllables and the preand posttonic syllables. In the prosodic words there is variation of 0 to 5 pretonic syllables and 1 to 2 posttonic syllables.

The sentences consist of: ${ }^{3}$

(i) short subjects (up to three syllables) that are prosodically nonbranching (only one $\omega)$ - see (3a);

(ii) long subjects (more than three syllables) that are non-branching prosodically - see (3b);

(iii) subjects composed of more than three syllables and prosodically branching (more than one $\omega)$ - see (3c);

(3) a. (os. Jo.vens) $\omega$

the (masc $_{\text {t }}$ teenagers

'the teenagers'

b. (as. ve.ne.zu.e.LA. $\underline{\underline{\text { nas }}}) \omega$

the ${ }_{(\mathrm{fem})}$ Venezuelans $_{(\mathrm{fem})}$

'the Venezuelans'

c. (as. BI.o $) \omega$ (MÉ.di.cas $) \omega$

the $_{(\mathrm{fem})}$ biomedical laboratory technicians $\mathrm{fem}_{(\mathrm{em})}$

'the biomedical laboratory technicians'

(as. ‥LU. $\underline{\underline{n a s}} \omega($ JO.vens) $\omega$

the (fem) $_{\text {students }}$ (fem) $_{\text {young }}$

'the young students'

Sentence predicates consist of:

(i) short predicates (up to three syllables) that are prosodically nonbranching (predicate composed of a single $\omega)$ - see (4a);

(ii) long predicates (more than three syllables) that are prosodically non-branching - see (4b);

(iii) predicates with more than three syllables that are prosodically branching - see $(4 c)$.

(4) a. (che.GA.ram $) \omega$

arrived

'arrived'

(RI.ram) $\omega$

laughed

'laughed'

\footnotetext{
${ }^{3}$ In the examples, parentheses mark $\omega$-boundaries; dots signal syllable limits; capital letters signal stressed syllables; underlined syllables indicate pretonic syllables; and double underlined syllables represent posttonic syllables.
} 
b. (a.dor.me.CE.ram) $\omega$

fell asleep

'fell asleep'

(tra.ba.LHA.ram) $\omega$

worked

'worked'

c. (che.GA.ram $) \omega($ HO.je $) \omega$

arrived today

'arrived today'

(RI.ram) $\omega($ HO.je $) \omega$

laughed today

'laughed today'

(la.vA.ram) $\omega$ (as. LU.vas) $\omega$

washed the (fem) $_{\text {gloves }}$ (fem)

'washed the gloves'

The control of these factors aims at investigating whether any of them may affect the tonal association of BP narrow-focus subject and neutral sentences. We will examine: (i) if the number of $\omega$ s that compose the $\phi s$ that contain subjects and predicate elements can affect the number of pitch accents associated with the intonational contour of narrow-focus subject and neutral sentences; (ii) if in the intonational contour of narrow-focus subject and neutral sentences, pitch accent types associated with $\omega$ s can vary according to the position they occupy within I and according to the number of syllables that they include; (iii) if the large number of pretonic syllables in a $\omega$ implies that a larger number of tones can be associated with it in the intonational contour of narrow-focus subject sentences, as occurs in the intonational contour of neutral sentences (as noted in previous analyses of the BP neutral contour); and (iv) if in narrow-focus subject sentence contours, there are no edgerelated tones associated with boundaries of prosodic domains other than those of I-domain (as has been noted for the neutral contour in previous analysis of $\mathrm{BP})$.

\subsection{Procedure}

The procedure followed here consisted in the recording of interviews with three female native speakers of $\mathrm{BP}(\mathrm{F}, \mathrm{G}$ and $\mathrm{T})$. The recordings were made at $16 \mathrm{kHz}$ with a Panasonic US 360 digital recorder. The three BP speakers are from Campinas (São Paulo State), belong to the same age-group (19 to 22 years old) and are all high school graduates. 
The recorded sentences were intonationally analyzed. For this task, we used the speech analysis software Praat. ${ }^{4}$ The intonational analysis consisted in the tonal transcription of the intonational contour, namely, the identification of local tonal events in the tonal string. The tonal transcription was based on Pierrehumbert (1980), Beckman \& Pierrehumbert (1986), Pierrehumbert \& Beckman (1988), and Ladd (1996) and also on the previously mentioned studies of Portuguese intonation developed within the autosegmental metrical theory of intonational phonology.

During the interviews, speakers were given sentences to read aloud, preceded by a context inducing the production of the neutral reading (see 5). They were also given questions to answer orally, preceded by a context inducing the production of subject-narrow-focus sentences (see 6). These two types of contexts were alternated with entertaining contexts or with the reading of entertaining sentences. Each context was presented separately.

[Contexto: Li a seguinte notícia:]
'Context: I read the following news:'

Os jovens riram.

the teenagers laughed

'The teenagers laughed.'

(6) [Contexto: Você sabe que os jovens riram quando assistiram à comédia na TV. Eu ouvi dizer que alguém riu, mas não sei exatamente quem riu, então, pergunto a você:

Quem riu?]

'Context: You know that the teenagers laughed when they watched the comedy on TV. I heard that somebody laughed, but I didn't understand who laughed. So, I ask you:

Who laughed?'

Os jovens riram.

the teenagers laughed

'The teenagers laughed.'

In the beginning of the interviews, speakers were instructed to produce sentences in a spontaneous way and answer the interview questions with what they considered to be a complete and natural sentence, according to the context given. The whole task was performed two times by each speaker. The total number of sentences produced by the three BP speakers was 672: (56 neutral sentences X 2 repetitions +56 sentences in subject-narrow-focus contexts $\mathrm{X} 2$ repetitions) $\mathrm{X} 3$ speakers.

\footnotetext{
${ }^{4}$ Boersma, P. \& Weenink, D. (1992-2005). Praat - doing phonetics by computer, software version 4.3 .02 (http://www.fon.hum.uva.nl/praat).
} 


\section{Results and discussion}

\subsection{The contour of neutral sentences in BP}

The total number of BP neutral sentences was 336:56 sentences X 2 repetitions X 3 speakers. As T produced one of the sentences with focus on the verb, we have discarded it, and therefore 335 sentences were analyzed.

We can identify as a global characteristic of this sort of sentence in BP the optional association of pitch accents to all $\omega s$. Aditionally, nearly all sentences show the obligatory presence of pitch accents associated with the $\omega s$ that are the head of $\phi .^{5}$ By contrast, we found no edge-related tones associated with prosodic domain boundaries different from the I-domain, as also noted in earlier studies on BP neutral intonation.

Figure 1 ilustrates a case of a pitch accent associated with each $\omega$ of the sentence represented in (7), whereas Figure 2 shows a case in which pitch accents are associated only with the heads of their corresponding $\phi s$, as in (8).

$$
\begin{aligned}
& {[[(\text { as aLUnas }) \omega(\text { JOvens }) \omega] \phi[(\text { cheGAram }) \omega(\text { HOje }) \omega] \phi]_{\perp}} \\
& \mathrm{L}^{*+\mathrm{H}} \mathrm{L}^{*+\mathrm{H}} \quad \mathrm{L}^{*+\mathrm{H}} \quad \mathrm{H}^{+\mathrm{L}^{*}}
\end{aligned}
$$

'The young students arrived today.'

[Context: I read the following news:]

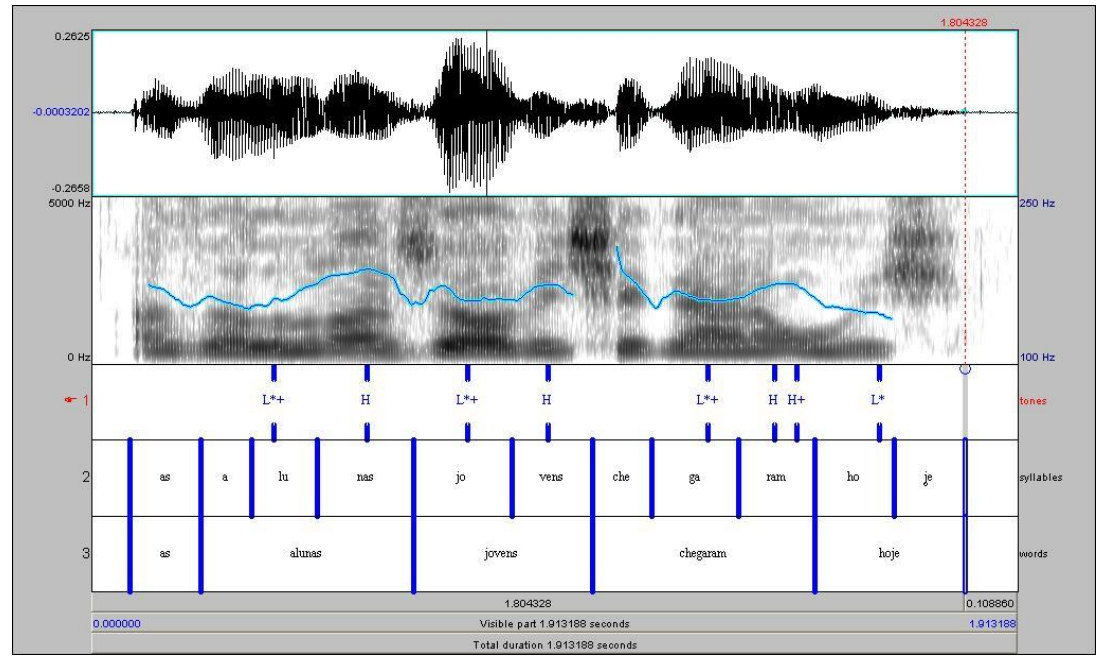

Figure $1 . \mathrm{F}_{0}$ contour of the neutral sentence As alunas jovens chegaram hoje 'The young students arrived today' produced by $\mathrm{F}$ in neutral context.

\footnotetext{
${ }^{5}$ We thank Sónia Frota for these observations.
} 
(8)

$$
\left[\left[\left.\operatorname{Las}_{\mathrm{L}^{*}+\mathrm{H}}\right|_{\mathrm{H}+\mathrm{L}^{*}} ^{\mid}\right.\right.
$$

'The biomedical laboratory technicians laughed today.' [Context: I read the following news:]

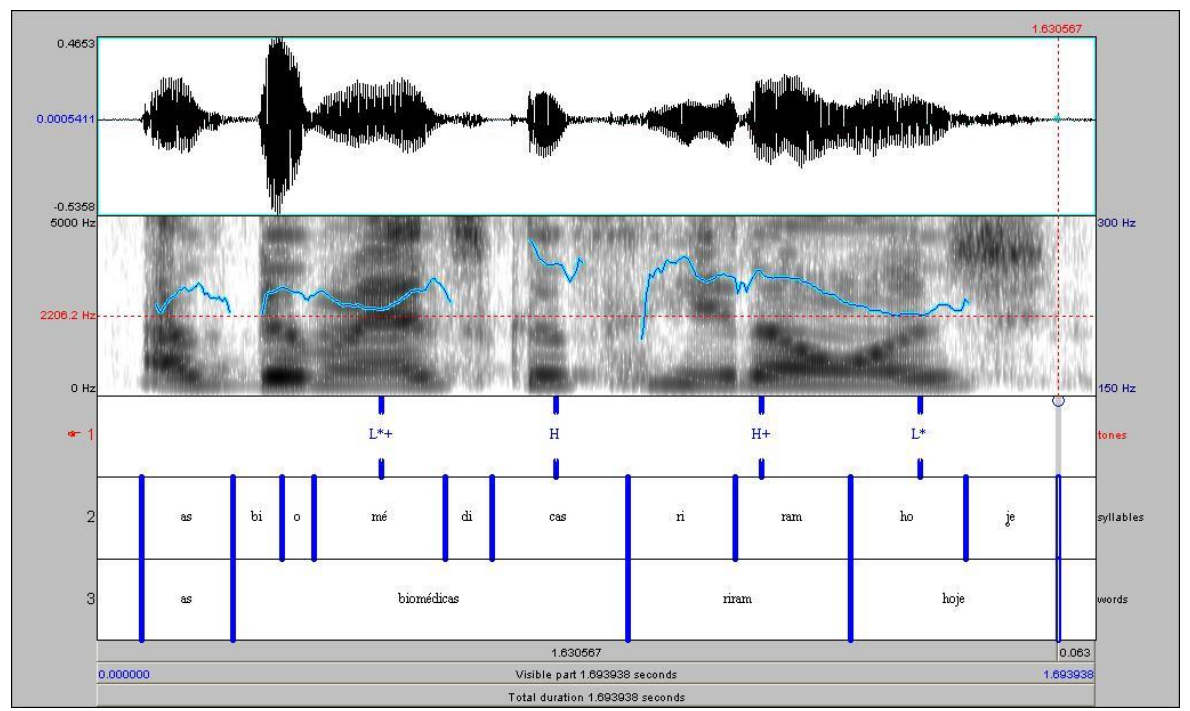

Figure 2. $\mathrm{F}_{0}$ contour of the neutral sentence As biomédicas riram hoje 'The biomedical laboratory technicians laughed today’ produced by $\mathrm{T}$ in neutral context.

The types of tones associated with $\omega$ s vary according to the position of $\omega \mathrm{s}$ within I, and the number of syllables forming the $\omega s$.

In most of our data, an $\mathrm{L}^{*}+\mathrm{H}$ was associated with the stressed syllable of the head of the first $\phi\left(97.3 \%\right.$ of our data). The $\mathrm{L}^{*}$ tone is aligned with the stressed syllable, and the $\mathrm{H}$ tone is systematically aligned with the immediate following syllable. An $\mathrm{H}^{*}$ can also appear aligned with the stressed syllable of the head of the first $\phi$, when that phrase is non-branching and consists of up to three syllables ( 1 pretonic syllable, 1 stressed syllable, and 1 posttonic syllable, as in $[($ os.JO.vens $\left.) \omega] \phi . ..]_{\mathrm{I}}\right)$. However, these cases are rare, as they appear in only $2.4 \%$ of the 84 sentences of this kind.

Table I presents the percentages of the tonal types associated with the head of the first non-branching $\phi$ of $\mathrm{I}$ in the sentences produced by the three speakers. In the tables presented in this paper, $\omega_{1}$ and $\omega_{2}$ stand for the first and second $\omega$ of branching $\phi s$, respectively; $[\omega] \phi_{\mathrm{P}}$ and $[\omega] \phi_{\mathrm{F}}$ indicate $\omega$ s belonging to the penult and to the final non-branching $\phi$ s, respectively; $\sigma$ and $\sigma$ correspond to unstressed and stressed syllables, respectively; ] $\phi$ represents right $\phi$-boundaries; (Li) indicates an $\mathrm{L} \%$ tone associated with the right 
I-boundary, whose presence/absence depends on the production of the last posttonic syllable.

\begin{tabular}{cccc}
\hline Speakers & $\mathrm{H}^{*}$ & $\mathrm{~L}^{*}+\mathrm{H}$ & Total \\
\hline $\mathrm{F}$ & $1.8 \%(1)$ & $98.2 \%(55)$ & $100.0 \%(56)$ \\
$\mathrm{G}$ & $0.0 \%(0)$ & $100.0 \%(56)$ & $100.0 \%(56)$ \\
$\mathrm{T}$ & $1.8 \%(1)$ & $98.2 \%(54)$ & $100.0 \%(55)$ \\
\hline
\end{tabular}

Table I. Tonal events associated with the head $\omega$ of the I-initial non-branching $\phi$ Percentages and number of tokens (in parenthesis).

Besides the $\mathrm{L}^{*}+\mathrm{H}$ pitch accent associated with the stressed syllable of $\omega$, the occurrence of an additional $\mathrm{H}$ tone aligned with the second or third pretonic syllable is also possible when the first non-branching $\phi$ is composed of a word with more than three pretonic syllables. We found this additional $\mathrm{H}$ tone associated with the third pretonic syllable (in $14.3 \%$ of the sentences of this kind produced by $\mathrm{G}$ and $7.4 \%$ of the sentences of this type produced by $\mathrm{T}$ ) or the second pretonic syllable (in $35.7 \%$ of the sentences produced by $\mathrm{G}$ and $14.8 \%$ of the sentences of this type produced by T). In this sort of sentence produced by $\mathrm{F}$, we did not find the $\mathrm{H}$ tone associated with the second or third pretonic syllables. Figure 3 corresponds to the intonational contour of the sentence As venezuelanas lavaram as luvas 'The Venezuelans washed the gloves', which is represented in (9). ${ }^{6}$ This sentence contour shows an additional $\mathrm{H}$ tone associated with the pretonic syllable 'ne' of a $\omega$ consisting of more than three pretonic syllables, (as.ve.ne.zu.e.LA.nas) $\omega$.

(9) $[[(\text { as venezueLAnas }) \omega] \phi[(\text { laVAram }) \omega] \phi[(\text { as LUvas }) \omega] \phi]_{\mathrm{I}}$

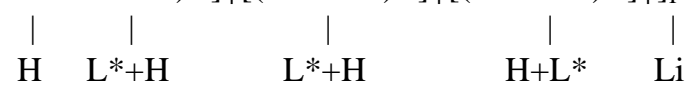

[Context: I read the following news:]

\footnotetext{
${ }^{6}$ In the tonal transcriptions in this paper: $\mathrm{Li}$ corresponds to the $\mathrm{L} \%$ boundary tone; $\mathrm{Lp}$ and $\mathrm{Hp}$ correspond, respectively, to the $\mathrm{L}^{-}$and $\mathrm{H}^{-}$phrase accents in Pierrehumbert's notation. Lp and $\mathrm{Hp}$ are associated with $\phi$-boundaries and $\mathrm{Li}$ is aligned to I-boundaries in our data.
} 


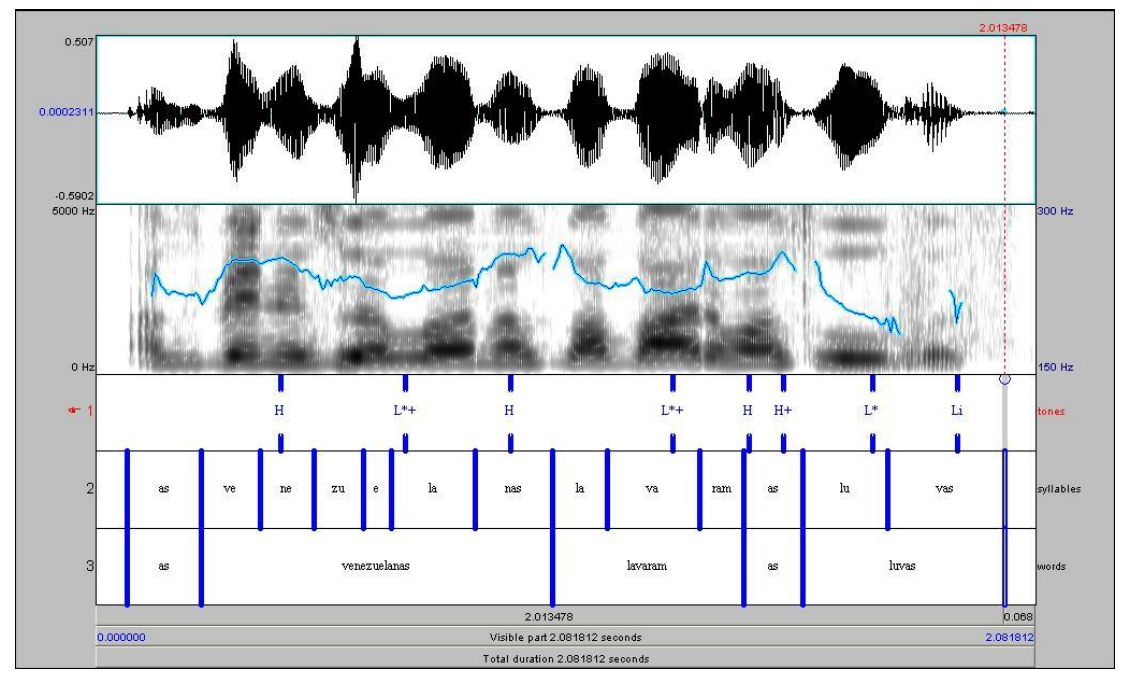

Figure 3. $\mathrm{F}_{0}$ contour of the neutral sentence As venezuelanas lavaram as luvas 'The Venezuelans washed the gloves' produced by $\mathrm{G}$ in neutral context.

When the first $\phi$ of $I$ is branching, i.e., composed of more than two $\omega$ s, it is possible to find one pitch accent associated with each $\omega$ of $\phi$ or only one pitch accent associated with the head of $\phi$. The association of pitch accents only with the first $\omega$ of branching- $\phi s$ is almost non-existent, as Table II shows. In this table, we present the percentages of the types of tonal association found in the neutral sentences composed of an initial branching- $\phi$, produced by each BP speaker.

\begin{tabular}{ccccccc}
\hline Speakers & $\begin{array}{c}\mathrm{H}^{*} \text { in } \\
\omega_{1}\end{array}$ & $\begin{array}{c}\mathrm{L}^{*}+\mathrm{H} \\
\text { in } \omega_{1}\end{array}$ & $\begin{array}{c}\mathrm{L}^{*}+\mathrm{H} \text { in } \\
\omega_{2}\end{array}$ & $\begin{array}{c}\mathrm{L}^{*}+\mathrm{H} \text { in } \\
\omega_{1} \text { and } \omega_{2}\end{array}$ & $\begin{array}{c}\mathrm{H}^{*} \text { in } \omega_{1} \\
\text { and } \mathrm{L}^{*}+\mathrm{H}\end{array}$ & Total \\
& & & & & & \\
in $\omega_{2}$ & \\
\hline $\mathrm{F}$ & $1.8 \%(1)$ & $1.8 \%(1)$ & $42.9 \%(24)$ & $44.6 \%(25)$ & $8.9 \%(5)$ & $100.0 \%(56)$ \\
$\mathrm{G}$ & $1.8 \%(1)$ & $0.0 \%(0)$ & $26.8 \%(15)$ & $42.9 \%(24)$ & $28.5 \%(16)$ & $100.0 \%(56)$ \\
$\mathrm{nyyyyyy} \mathrm{T}$ & $7.1 \%(4)$ & $0.0 \%(0)$ & $41.1 \%(23)$ & $33.9 \%(19)$ & $17.9 \%(10)$ & $100.0 \%(56)$ \\
\hline
\end{tabular}

Table II. Tonal events associated with each $\omega$ of the I-initial branching $\phi$.

The results in Table II show that the association of one pitch accent with each $\omega$ of an initial branching- $\phi$ is dominant when compared to the association of a pitch accent exclusively with the head of $\phi$. 
For the final contour of neutral sentences, we always found an $\mathrm{H}+\mathrm{L}^{*}$ associated with the head of the last $\phi$ of I, and an Li boundary tone associated with the final I-boundary, when the last posttonic syllable is produced (see Figures 1, 2 and 3). The $\mathrm{H}$ tone is systematically aligned with the immediate pretonic syllable and the $\mathrm{L}^{*}$ tone is systematically aligned with the stressed syllable.

As was noted for the I-initial branching $\phi$, when the I-final $\phi$ is branching, we also found one pitch accent associated with each $\phi$-internal $\omega$, or a single $\mathrm{H}+\mathrm{L}^{*}$ associated with the head of that $\phi$.

The results in Table III indicate that the association of pitch accent exclusively with the head of the last $\phi$ is dominant in the data of $\mathrm{F}$ and $\mathrm{T}(66.7 \%$ in F's data, and $52.2 \%$ in T's data). Nevertheless, there is a clear preference for pitch accent association with each $\omega$ of the last $\phi$ in G's data (79.2\%).

\begin{tabular}{cccccc}
\hline Speakers & $\begin{array}{c}\mathrm{L}^{*}+\mathrm{H} \text { in } \omega_{1} \\
\text { and } \mathrm{H}+\mathrm{L}^{*} \\
\text { in } \omega_{2}\end{array}$ & $\begin{array}{c}\mathrm{H}+\mathrm{L}^{*} \text { in } \omega_{1} \\
\text { and } \mathrm{H}+\mathrm{L}^{*} \\
\text { in } \omega_{2}\end{array}$ & $\begin{array}{c}\mathrm{L} * \text { in } \omega_{1} \\
\text { and } \mathrm{H}+\mathrm{L}^{*}\end{array}$ & $\begin{array}{c}\mathrm{H}+\mathrm{L}^{*} \text { in } \\
\text { in } \omega_{2}\end{array}$ & Total \\
\hline \hline $\mathrm{F}$ & $29.2 \%(7)$ & $4.2 \%(1)$ & $0.0 \%(0)$ & $66.6 \%(16)$ & $100.0 \%(24)$ \\
\cline { 2 - 6 } $\mathrm{G}$ & $79.2 \%(19)$ & $0.0 \%(0)$ & $0.0 \%(0)$ & $20.8 \%(5)$ & $100.0 \%(24)$ \\
\cline { 2 - 6 } $\mathrm{T}$ & $34.8 \%(8)$ & $8.7 \%(2)$ & $4.3 \%(1)$ & $52.2 \%(12)$ & $100.0 \%(23)$
\end{tabular}

Table III. Tonal events associated with each $\omega$ of the I-final branching $\phi$.

The results in Table IV show that the presence of one pitch accent associated with the heads of final and penultimate non-branching $\phi \mathrm{s}$ is almost obligatory in the BP data (91.7\% in F's and T's data and $100.0 \%$ in G's data).

\begin{tabular}{cccccc}
\hline Speakers & $\mathrm{L}^{*}+\mathrm{H}$ in & $\mathrm{H}+\mathrm{L}^{*}$ in & $\mathrm{L} *$ in & $\mathrm{H}+\mathrm{L}^{*}$ in & Total \\
& {$[\omega] \phi_{\mathrm{P}}$ and } & {$[\omega] \phi_{\mathrm{P}}$ and } & {$[\omega] \phi_{\mathrm{P}}$ and } & {$[\omega] \phi_{\mathrm{F}}$} & \\
& $\mathrm{H}+\mathrm{L} *$ in & $\mathrm{H}+\mathrm{L} *$ in & $\mathrm{H}+\mathrm{L} *$ in & & \\
& {$[\omega] \phi_{\mathrm{F}}$} & {$[\omega] \phi_{\mathrm{F}}$} & {$[\omega] \phi_{\mathrm{F}}$} & & \\
\hline \hline $\mathrm{F}$ & $91.7 \%(22)$ & $0.0 \%(0)$ & $0.0 \%(0)$ & $8.3 \%(2)$ & $100.0 \%(24)$ \\
\cline { 2 - 6 } $\mathrm{G}$ & $100.0 \%(24)$ & $0.0 \%(0)$ & $0.0 \%(0)$ & $0.0 \%(0)$ & $100.0 \%(24)$ \\
\cline { 2 - 6 } $\mathrm{T}$ & $91.7 \%(22)$ & $0.0 \%(0)$ & $0.0 \%(0)$ & $8.3 \%(2)$ & $100.0 \%(24)$ \\
\hline
\end{tabular}

Table IV. Tonal events associated with the ws of the penult and the I-final non-branching $\phi$ s. 
We should also note that, in sentence predicates, the types of pitch accents associated with $\omega$ s vary according to their position within I. There is always an $\mathrm{H}+\mathrm{L}^{*}$ pitch accent associated with the prominent $\omega$ of a final $\phi$, whereas a different type of pitch accent (for example, an $\mathrm{L}^{*}+\mathrm{H}$ tone) can be associated with non-promient $\omega$ s of a final $\phi$.

Our data confirm the description found in the literature of the final falling contour of BP neutral declaratives (Cunha, 2000; Frota \& Vigário, 2000; Tenani, 2002). There is always an $\mathrm{H}+\mathrm{L}^{*}$ associated with the head of the last $\phi$ and an $\mathrm{L} \%(\mathrm{Li})$ associated with the rigth boundary of $\mathrm{I}$ (when the last posttonic syllable is produced). As in EP, the $\mathrm{H}+\mathrm{L}^{*}$ associated with the head of the last $\phi$ is the main characteristic of the final contour of BP declarative sentences, as noted earlier by Cunha (2000) and Tenani (2002) for the latter variety of Portuguese.

Our results also confirm those found by Frota \& Vigário (2000) and Tenani (2002) regarding the nearly obligatory association of pitch accents with the heads of $\phi s$ and the possible occurrence of an additional $\mathrm{H}$ tone associated with the pretonic syllables that are non-adjacent to the stressed syllable, in $\omega$ s with more than three pretonic syllables in BP neutral sentences. In addition to the results of these earlier works, we found pitch accents that are associated with non-promient $\omega \mathrm{s}$, besides the nearly obligatory pitch accent association to the heads of $\phi$.

Our data also endorse the results of Frota \& Vigário (2000) and Tenani (2002) regarding the preferential L H L H tonal pattern and the absence of edge-related tones associated with boundaries of domains different from the I-domain in the contour of neutral declaratives in BP.

\subsection{The contour of basic word order sentences with focus on the subject in BP}

$336 \mathrm{BP}$ sentences were produced with basic word order in the context of narrow-focus on the subject: 56 sentences X 2 repetitions X 3 speakers. However, of these we analyzed only 272 . This is because F produced prosodic focus on an element different from the subject in four sentences, prosodic focus on the subject and on an element different from the subject in two sentences and the same intonational pattern in neutral sentences in one of the sentences; $\mathrm{T}$ produces the same intonational pattern in neutral sentences in one; and $\mathrm{G}$ produced sentences with prosodic focus on the subject only in the second interview, as opposed to the neutral intonation. Subject-focus sentences totaled 56 sentences produced by this speaker. Although instructions to take question contexts into account had been given at the beginning of the first interview, we believe that $G$ realized this only in the second interview.

The cases in which the speakers produced the same intonational pattern of neutral sentences were discarded from the analysis. This is because in BP the neutral pattern is not appropriate in contexts of narrow-focus subject 
expression, at least according to the judgement of BP native speakers, including the author of this paper.

The 272 sentences obtained for the cotext of narrow focus on the subject were produced with the main prominence on the focused element, and in the basic word order patterns (SV, SVO, SVAdv). In fact, this was the only option chosen by our speakers for focalizing the subject in the 272 sentences analysed here. The other existing manners of expressing focus on subject in BP were not used, for example:

(10) [As answers to the question 'Who died?']

a. it-cleft sentences: Foram os Jovens que morreram.

were the teenagers that died

'It was THE TEENAGERS that died.'

b. inverse it-cleft sentences: Os JOVENS é que morreram.

the teenagers is that died

'THE TEENAGERS died.'

c. reduced cleft sentences: OS JOVENS que morreram.

the teenagers that died

'THE TEENAGERS died'.

The initial contour of the 272 BP subject-narrow-focus sentences analysed may be characterized by the following intonational features:

(i) In the cases where the focused subject is constituted by a nonbranching $\phi$, there is a pitch accent always associated with the stressed syllable of the $\omega$ that constitutes the $\phi$, and an optional phrasal accent associated with the right boundary of this same $\phi$.

(ii) In the cases where the focused subject is constituted by a branching $\phi$ :

a. there can be a pitch accent associated with each $\omega$ that constitutes the $\phi$, and an optional phrasal accent associated with the right boundary of this phrase; or

b. there is a pitch accent associated with the head of the $\phi$ that contains the focused subject, and a phrasal accent is optionally associated with the right boundary of this same $\phi$.

The representation in (11) corresponds to case (i). In this representation, there is a pitch accent associated with the stressed syllable of the $\omega$ that constitutes the focused subject, and no phrasal accent associated with the right boundary of the $\phi$ that contains this $\omega$. In figure 4 , we can see the alignment of the $\mathrm{H}^{*}$ tone with the stressed syllable of the $\omega$ that constitutes the focused subject, and the alignment of the $\mathrm{L}$ tone with the immediate following syllable. This kind of regular alignment allows us to interpret this tonal pattern 
as an $\mathrm{H}^{*} \mathrm{~L}$, which is associated with the focused element (like in EP, as noted by Frota, 2002b).

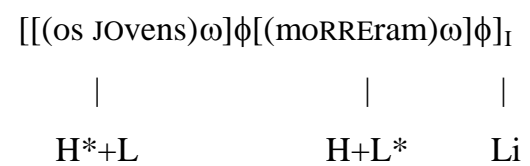

'The teenagers died.'

[Context: Who died?]

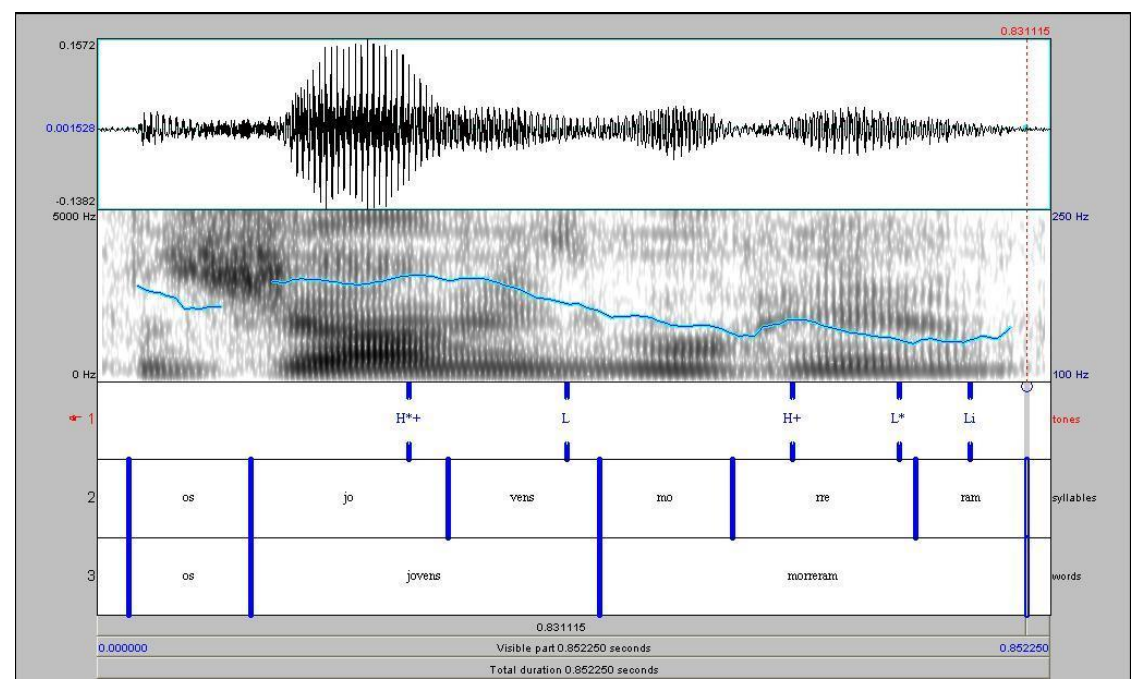

Figure 4. $\mathrm{F}_{0}$ contour of the subject-focus sentence Os jovens morreram 'The teenagers died' produced by $\mathrm{F}$ in the context of narrow-focus on the subject.

The representation in (12) illustrates case (iia). In (12), there is an $\mathrm{L}^{*}+\mathrm{H}$ pitch accent associated with each $\omega$ of the $\phi$ that contains the focused subject, followed by the association of an Lp phrasal accent to the right boundary of the same $\phi$. In general, the $\mathrm{L}^{*}$ tones are aligned with the stressed syllables, the $\mathrm{H}$ tones are aligned with the immediate following syllables, and, as exemplified in Figure 5, the Lp tone is aligned with the first syllable of the next $\phi$ (or to the end of the last syllable of the $\phi$ that contains the focused subject). 
$[[(\text { as meNInas }) \omega(\text { BElas }) \omega] \phi[(\text { lavAram }) \omega(\text { as LUvas }) \omega] \phi]_{\text {I }}$

$\begin{array}{clc}\text { l } & \text { | } & \text { | } \\ \mathrm{L}^{*}+\mathrm{H} & \mathrm{L}^{*}+\mathrm{HLp} & \mathrm{Li}\end{array}$

'The beautiful girls washed the gloves.'

[Context: Who washed the gloves?]

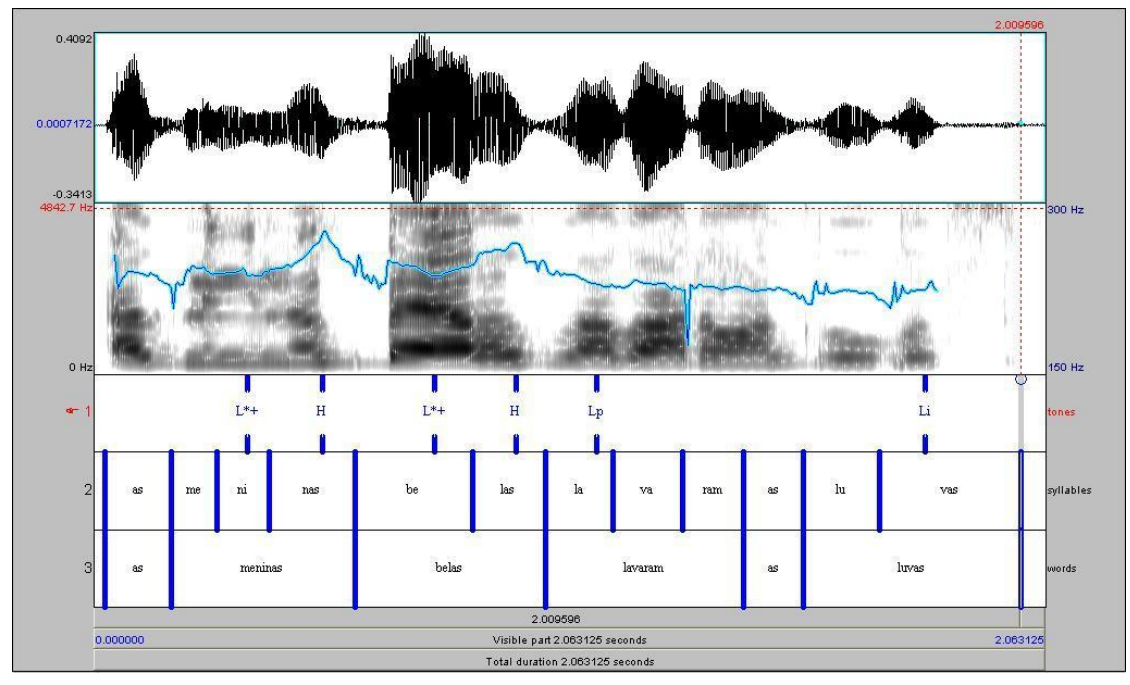

Figure $5 . \mathrm{F}_{0}$ contour of the subject-focus sentence As meninas belas lavaram as luvas 'The beautiful girls washed the gloves' produced by $\mathrm{T}$ in the context of narrow-focus on the subject.

The representation in (13) illustrates case (iib). In (13), there is an $\mathrm{L}^{*}+\mathrm{H}$ pitch accent associated with the head of the $\phi$ that contains the focused subject, followed by the association of an Lp phrasal accent with the right boundary of that same $\phi$. The $\mathrm{L}^{*}$ tone is aligned with the stressed syllable of the prominent $\omega$ of $\phi$, the $\mathrm{H}$ tone is aligned with the immediate following syllable, and the Lp tone is aligned with the first syllable of the next $\phi$, as shown in figure 6 . 
With respect to the type of pitch accents associated with the narrow-focus subject, when the $\phi$ that includes the focused subject is formed of only one $\omega$ with up to three syllables ( $\sigma \mathrm{s})$ ( 1 pretonic $\sigma, 1$ stressed $\sigma$ and 1 posttonic $\sigma$ ), we found: (i) either the association of an $\mathrm{H}^{*}+\mathrm{L}$ pitch accent with the stressed $\sigma$ of $\omega$; or (ii) the association of an $\mathrm{L}^{*}+\mathrm{H}$ pitch accent with the stressed $\sigma$ of the $\omega$, followed by the association of an Lp phrasal tone with the right $\phi$ boundary.

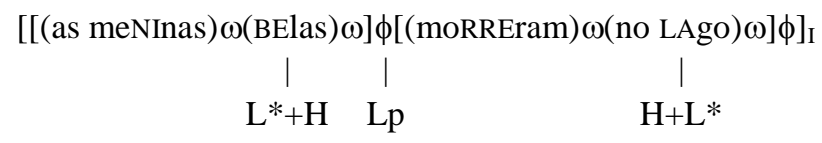

'The beautiful girls died in the lake.'

[Context: Who died in the lake?]

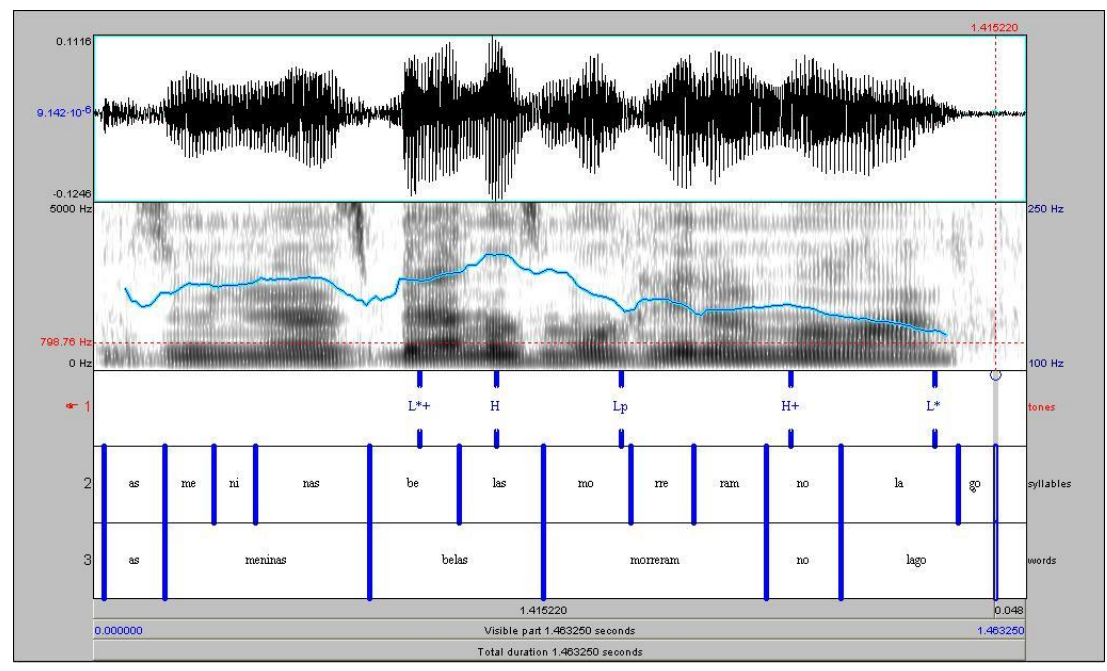

Figure 6. $\mathrm{F}_{0}$ contour of the subject-focus sentence As meninas belas morreram no lago 'The beautiful girls died in the lake' produced by $\mathrm{F}$ in the context of narrow-focus on the subject.

The results in Table $\mathrm{V}$ show that the type of tonal association presented in (i) is dominant in F's data $(58.3 \%$ of the data), that the tonal association presented in (ii) is dominant in T's data $(96.3 \%)$, and that both kinds of tonal association occur in the same proportion in G's data $(50.0 \%$ of each type of tonal association). 


\begin{tabular}{cccl}
\hline Speakers & $\begin{array}{c}{[(. \sigma \sigma . .) \omega] \phi} \\
\end{array}$ & $\begin{array}{c}{[(. . \sigma \sigma . .) \omega] \phi} \\
\text { | }\end{array}$ & Total \\
& $\mathrm{L}^{*}+\mathrm{H} \mathrm{Lp}$ & $\mathrm{H}$ & \\
\hline \hline $\mathrm{F}$ & $41.7 \%(10)$ & $58.3 \%(14)$ & $100.0 \%(24)$ \\
\cline { 2 - 4 } $\mathrm{G}$ & $50.0 \%(7)$ & $50.0 \%(7)$ & $100.0 \%(14)$ \\
\cline { 2 - 4 } $\mathrm{T}$ & $96.3 \%(26)$ & $3.7 \%(1)$ & $100.0 \%(27)$ \\
\hline
\end{tabular}

Table V. Tonal events associated with the initial part of the sentence contour in the context of narrow-focus on the subject, when the $\phi$ that contains the subject is non-branching and formed of up to three syllables $(\sigma)$ (1 pretonic, 1 stressed and 1 posttonic os) and in which the subject forms a non-branching $\phi$.

Nevertheless, when the $\phi$ to which the focused subject belongs is composed of only one $\omega$ consisting of more than three pretonic syllables (4 or 5 pretonic $\sigma \mathrm{s}, 1$ stressed $\sigma$, and 1 posttonic $\sigma$ ), we found that: either (i) an $\mathrm{H}+\mathrm{L}$ pattern is found associated with the immediate pretonic syllables of the $\omega(\mathrm{H}$ aligned with the second pretonic $\sigma$, and $\mathrm{L}$ aligned with the first pretonic $\sigma)$; or (ii) a pitch accent $\left(\mathrm{L}^{*}+\mathrm{H}\right.$ or $\left.\mathrm{H}+\mathrm{L}^{*}\right)$ is associated with the stressed syllable, and a phrasal tone (Lp or Hp) with the right edge of $\phi$. Table VI presents the percentage of occurrence of the different types of tonal association in our data for each BP speaker.

\begin{tabular}{ccccccc}
\hline Speakers & {$[(. . \sigma \sigma ..) \omega] \phi$} & {$[(. . \sigma \sigma ..) \omega] \phi$} & {$[(. . \sigma \sigma ..) \omega] \phi$} & {$[(. . \sigma \sigma ..) \omega] \phi$} & Total \\
& $\begin{array}{c}\mid \\
\end{array}$ & | & | & $\mid$ & $\mid$ \\
& $\mathrm{L}^{*}+\mathrm{H}$ & $\mathrm{Lp}$ & $\mathrm{H}+\mathrm{L}$ & $\mathrm{H}+\mathrm{L}^{*} \mathrm{Hp}$ & $\mathrm{H}+\mathrm{L}^{*} \mathrm{Lp}$ & \\
\hline \hline $\mathrm{F}$ & $96.2 \%(25)$ & $0 \%(0)$ & $3.8 \%(1)$ & $0.0 \%(0)$ & $100.0 \%(26)$ \\
\cline { 2 - 7 } $\mathrm{G}$ & $28.6 \%(4)$ & $21.4 \%(3)$ & $21.4 \%(3)$ & $28.6 \%(4)$ & $100.0 \%(14)$ \\
\cline { 2 - 7 } $\mathrm{T}$ & $10.7 \%(3)$ & $0.0 \%(0)$ & $89.3 \%(25)$ & $0.0 \%(0)$ & $100.0 \%(28)$ \\
\hline
\end{tabular}

Table VI. Tonal events associated with the initial contour of the sentences with narrow-focus on the subject, in which the focused subject is formed of more than three pretonic os (4 pretonic, 1 stressed and 1 posttonic) and in which the subject forms a non-branching $\phi$.

The results in Table VI show that the pitch accent association with the prominent $\sigma$ of $\omega$, followed by a phrasal tone association with the right $\phi$ boundary, is predominant in the data produced by the three BP speakers when the focused subject consists of more than three pretonic $\sigma \mathrm{s}$. $\mathrm{F}$ and $\mathrm{T}$ present 
this sort of tonal association in $100.0 \%$ of the cases (result of the sum of the percentages of F's data presented in first, third and fourth columns, and result of the sum of the percentages of T's data presented in the same columns), and $\mathrm{G}$ presents the same type of tonal association in $78.6 \%$ of the cases (result of the sum of the percentages of G's data presented in the same columns).

As for the $\mathrm{H}+\mathrm{L}$ tonal sequence exhibited by $\mathrm{G}$, we interprete it as a case of early $\mathrm{H}^{*}+\mathrm{L}$ association, favoured by the large number of pretonic syllables composing the focused subject. ${ }^{7}$

As noted for the neutral sentences, we also found an additional $\mathrm{H}$ tone associated with the second or third pretonic syllable of the $\omega$ that composes the subject, aside from the $\mathrm{L}^{*}+\mathrm{H}$ pitch accent associated with the stressed syllable and the Lp phrasal accent associated with the right boundary of the $\phi$ that contains the focused subject. We found an additional $\mathrm{H}$ tone associated with the second pretonic syllable in $19.2 \%$ of F's data, an $\mathrm{H}$ tone associated with the second pretonic syllable in $7.1 \%$ of G's data, and an $\mathrm{H}$ tone associated with the third pretonic syllable in $7.1 \%$ of G's data.

When the $\phi$ that includes the focused subject is branching, we found the following possibilities: (i) a pitch accent is associated with each $\omega$ of $\phi$, and a phrasal tone is associated with the right edge of $\phi$; (ii) only a pitch accent is associated with each $\omega$ of the $\phi$; (iii) a pitch accent is associated with the head $\omega$ of $\phi$; (iv) a pitch accent is associated with the head of $\phi$ and a phrasal tone is associated with the right boundary of $\phi$.

\begin{tabular}{cccccccc}
\hline Speakers & $\mathrm{L}^{*}+\mathrm{H}$ or & $\mathrm{L}^{*}+\mathrm{H}^{*}$ & $\mathrm{~L}^{*}+\mathrm{H}$ in & $\mathrm{L}^{*}+\mathrm{H}$ or & $\mathrm{L}^{*}+\mathrm{H}$ in & $\mathrm{H}+\mathrm{L}^{*}$ in & Total \\
& $\mathrm{H}^{*}$ in & in $\omega_{1}$ and & $\omega_{2}$ & $\mathrm{H}^{*}$ in $\omega_{1}$, & $\omega_{2}$ and $\mathrm{Lp}$ & $\omega_{2}$ and & \\
& $\omega_{1}$ and & $\mathrm{H}^{*}+\mathrm{L}$ in & & $\mathrm{L}^{*}+\mathrm{H}$ in & in $] \phi$ & $\mathrm{Lp}$ in $] \phi$ & \\
& $\mathrm{L}^{*}+\mathrm{H}$ in & $\omega_{2}$ & & $\omega_{2}$ and $\mathrm{Lp}$ & & & \\
& $\omega_{2}$ & & & in $] \phi$ & & & \\
\hline $\mathrm{F}$ & $3.6 \%(2)$ & $3.6 \%(2)$ & $1.8 \%(1)$ & $43.7 \%(24)$ & $47.3 \%(26)$ & $0.0 \%(0)$ & $100.0 \%(55)$ \\
$\mathrm{G}$ & $3.5 \%(1)$ & $10.8 \%(3)$ & $0.0 \%(0)$ & $85.7 \%(24)$ & $0.0 \%(0)$ & $0.0 \%(0)$ & $100 \%(28)$ \\
$\mathrm{T}$ & $1.8 \%(1)$ & $1.8 \%(1)$ & $0.0 \%(0)$ & $89.2 \%(50)$ & $3.6 \%(2)$ & $3.6 \%(2)$ & $100.0 \%(56)$
\end{tabular}

Table VII. Tonal events associated with the initial contour of the sentences with narrow-focus on the subject, in which the subject forms a branching $\phi$

The results shown in Table VII indicate that the tonal associations composed of pitch accents associated with $\omega$ s followed by the phrasal tone associated with the right $\phi$-boundary, are predominant in our data. For F, this kind of tonal association is found in $90.8 \%$ of the productions (result of the

\footnotetext{
${ }^{7}$ We thank Sónia Frota for drawing our attention to this point.
} 
sum of the percentages of the $\mathrm{F}$ data presented in fourth, fifth and sixth columns), for $\mathrm{T}$ it is found in $96.4 \%$ of the data (result of the sum of the percentages of the $\mathrm{T}$ data presented in the same columns) and for $\mathrm{G}$ it represents $85.7 \%$ of the data (result of the sum of the percentages of the $G$ data presented in the same columns).

In all sentences with narrow-focus on the subject, we found no pitch accents associated with the intermediate $\omega$ s between the head of the $\phi$ that contains the focused subject and the last $\phi$ of I (see Figures 5 and 6 as illustrations).

As to the final part of the contour of the sentences with narrow-focus on the subject, an $\mathrm{H}+\mathrm{L}^{*}$ may be associated with the head of the last $\phi$ of $\mathrm{I}$, and a Li boundary tone associated with the final I-boundary. However, the picth accent may also be absent, in which case only an Li boundary tone is associated with the final I-boundary (see Figure 5).

\begin{tabular}{cccc}
\hline Speakers & $\mathrm{H}+\mathrm{L}^{*}(\mathrm{Li})$ & $\mathrm{Li}$ & Total \\
\hline \hline $\mathrm{F}$ & $23.8 \%(25)$ & $76.2 \%(80)$ & $100.0 \%(105)$ \\
\cline { 2 - 4 } $\mathrm{G}$ & $19.6 \%(11)$ & $80.4 \%(45)$ & $100.0 \%(56)$ \\
\cline { 2 - 4 } $\mathrm{T}$ & $7.2 \%(8)$ & $92.8 \%(103)$ & $100.0 \%(111)$ \\
\hline
\end{tabular}

Table VIII. Tonal events associated with the final contour of the sentences with narrow-focus on the subject.

The results in table VIII reveal that the total absence of pitch accents associated with the $\omega \mathrm{s}$ following the $\phi$ containg the focused subject is dominant in our data (occurring in $76.2 \%$ of F's productions, $80.4 \%$ of G's productions and $92.8 \%$ of T's productions).

Independent of theoretical considerations, it is possible to say that our results support those found by Cagliari (1982) and Gonçalves (1997) regarding the contour shape of narrow-focus sentences in BP and the difference between the contour shape of neutral and narrow-focus sentences. Like Cagliari (1982) and Gonçalves (1997), we also found contrasts between the intonational contour shape of neutral and narrow-focus sentences. The intonational contour of emphatic assertion described by Cagliari (1982) is one of the types of narrow-focus sentence contours found here: a convex intonational contour on the focused element and a falling contour after this element until the end of the sentence (see Figures 5 and 6). In addition to contour shape contrasts, our results show tonal association pattern differences between the neutral and narrow-focus subject intonational contours.

In contrast to the tonal association present in BP neutral sentences, in BP narrow-focus subject sentences we note that: 
1) Subjects under narrow-focus may either carry pitch accents different from those that are found in neutral contexts $\left(\mathrm{H}^{*}+\mathrm{L}\right.$ versus $\mathrm{L}^{*}+\mathrm{H}$ ) or may bear the same type of pitch accent as they bear in neutral contexts $\left(\mathrm{L}^{*}+\mathrm{H}\right)$;

2) If the narrow-focus subject is composed of a $\omega$ containing more than three pretonic syllables, the types of pitch accent association with the $\omega$ can be affected (for instance, we find the $\mathrm{H}+\mathrm{L}$ tonal sequence associated with the immediate pretonic syllable, instead of the $\mathrm{H}^{*}+\mathrm{L}$ tonal sequence associated with the stressed syllable of the $\omega)$;

3) There are no pitch accents associated with I-internal $\omega s$ ( $\omega s$ between the heads of initial and final $\phi s$ ), independently of the number of $\omega$ s that follow the subject's $\omega$-head;

4) A phrasal accent can be associated with the right boundary of the $\phi$ that contains the subject.

\section{Final considerations: a comparison of EP and BP intonational structures}

If we compare our results for $\mathrm{BP}$ with the EP intonational patterns described in the literature, we note that pitch accents are optionally associated with all $\omega s$ in the BP neutral sentence contour, whereas pitch accents are largely associated with the initial and final $\omega$ s of I in the EP neutral sentence contour.

Although the pitch accent association with all $\omega$ s is optional, it is nearly obligatory with the heads of $\phi$ in BP neutral sentence contours. A partially similar fact is also noted by Frota $(2000,2003)$ for EP, since according to her in this variety of Portuguese, if there is only a pitch accent association in a branching- $\phi$, the pitch accent is associated with the head of $\phi$.

Another similar feature between the two varieties of Portuguese is the final intonational contour of neutral sentences: an $\mathrm{H}+\mathrm{L}^{*}$ pitch accent is associated with the last $\phi$ of I, followed by an Li boundary tone association with the final I-boundary.

For the intonational contour of EP narrow-focus subjects, an $\mathrm{H}^{*}+\mathrm{L}$ bitonal pitch accent carried by the focused subject (the main characteristic of EP narrow-focused elements) is always present, but phrasal tones associated with the right boundary of the $\phi$ that contains the focused subject are non-existent By contrast, in BP there can be a special bitonal pitch accent carried by the focused subject $\left(\mathrm{H}^{*}+\mathrm{L}\right.$ or $\left.\mathrm{H}+\mathrm{L}^{*}\right)$, which is different from the pitch accent that the non-focused subject bears; but there can also be the occurrence of the same type of pitch accent carried by the non-focused subject and the occurrence of a phrasal accent associated with the right boundary of the $\phi$ that contains the focused subject. For the final contour of the subject-focus sentences, BP and EP present the same intonational properties: an $\mathrm{H}+\mathrm{L} *$ pitch 
accent is associated with the head of the last $\phi$ of the sentence, followed by $\mathrm{Li}$ boundary tone associatiated with the final I-boundary, or simply an Li boundary tone is associated with the final I-boundary.

Based on the results presented here, we can conclude that EP and BP present tonal association differences not only in neutral sentence contours, but also in narrow-focus subject sentence contours. Although both Portuguese varieties can present the same kind of narrow-focus subject expression, namely, sentences displaying basic word order and main prominence on the subject, the two varieties may differ in what concerns the kind of tonal association with the narrow-focus subject.

\section{Acknowledgements}

We would like to thank the reviewers and editors of this volume for their helpful suggestions and comments on previous versions of this paper; Sónia Frota for her helpful and essential comments on the intonational analysis of the BP data; William Pickering for English correction; and the BP speakers for their patience in recording the data. We also thank the Fundação de Amparo à Pesquisa do Estado de São Paulo and the Coordenação de Aperfeiçoamento de Pessoal de Nível Superior for financial support in the development of this research.

\section{References}

Âmbar, M. M. (1992) Para uma sintaxe da inversão sujeito-verbo em Português. Lisboa: Edições Colibri.

Beckman, M. \& Pierrehumbert, J. (1986) Intonational Structure in Japanese and English, Phonology Yearbook, 3, 255-310.

Cagliari, L. C. (1980) A entoação do Português Brasileiro, Estudos Lingüísticos, 3, 308-329.

Cagliari, L. C. (1982) Aspectos acústicos da entoação do português brasileiro, Série Estudos, 8, 45-59.

Costa, J. (1998) Word Order Variation. A constaint-based approach. Netherlands: Holland Academic Graphics.

Costa, J. \& Galves, C. (2002) External subjects in two varieties of Portuguese evidence for a non-unified analysis. In Romance languages and linguistic theory 2000 (C. Beyssade, R. Bok-Bennema, F. Drijkoningen \& P. Monachesi, editors), Vol. 232, pp. 109-125. Amsterdam/Philadelphia: John Benjamins Publishing Company.

Cunha, G. (2000) Entoação regional no Português do Brasil. Unpublished Ph.D. dissertation, Universidade Federal do Rio de Janeiro.

Delgado Martins, M. R. \& Lacerda, F. (1977) Para uma gramática da entoação. Paper given at the Congresso de Filologia e Lingüística, Rio de Janeiro.

Duarte, I. (1987) A Construção de Topicalização na Gramática do Português. Unpublished Ph.D. dissertation, Universidade de Lisboa. 
Falé, I. (1995) Fragmento da prosódia do Português Europeu: as estruturas coordenadas. Unpublished MA dissertation, Universidade de Lisboa.

Fernandes, N. H. (1976) Contribuição para uma análise instrumental da acentuação e intonação do Português. Unpublished MA dissertation, Universidade Estadual de São Paulo.

Frota, S. (1991) Para a prosódia da frase: quantificador, advérbio e marcação prosódica. Unpublished MA dissertation, Universidade de Lisboa.

Frota, S. (1993) On the prosody of focus in European Portuguese. In Proceedings of the Workshop on Phonology, pp. 45-66. Lisboa: APL.

Frota, S. (1997) On the prosody and intonation of focus in European Portuguese. In Issues in the Phonology and Morphology of the Major Iberian Languages (F. Martínez-Gil \& A. Morales-Front, editors), pp. 359-392. Washington, D.C.: Georgetown University Press.

Frota, S. (2000) Prosody and focus in European Portuguese. Phonological phrasing and intonation. New York: Garland Publishing.

Frota, S. (2002a) Nuclear falls and rises in European Portuguese: a phonological analysis of declarative and question intonation, Probus, 14(1), 113-146.

Frota, S. (2002b) Tonal association and target alignment in European Portuguese nuclear falls. In Laboratory Phonology 7 (C. Gussenhoven \& N. Warner, editors), pp. 387-418. Berlin/New York: Mouton de Gruyter.

Frota, S. (2003) The phonological status of initial peaks in European Portuguese, Catalan Journal of Linguistics, 2, 133-152.

Frota, S. \& Vigário, M. (2000) Aspectos de prosódia comparada: ritmo e entoação no $\mathrm{PE}$ e no PB. In Actas do XV Encontro Nacional da Associação Portuguesa de Linguística (R. V. Castro \& P. Barbosa, editors), pp. 533-555. Coimbra: APL.

Gebara, E. S. (1976) Alguns aspectos da intonação no Português. Unpublished MA dissertation, Universidade Estadual de Campinas.

Gonçalves, C. A. V. (1997) Focalização no Português do Brasil. Unpublished Ph.D. dissertation, Universidade Federal do Rio de Janeiro.

GrØnnum, N. \& Viana, M. C. (1999) Aspects of European Portuguese Intonation. In ICPhS 99 (J. Ohala, editor), Vol. 3, pp. 1997-2000. San Francisco.

Hayes, B. \& Lahiri, A. (1991) Bengali intonational phonology, Natural Language and Linguistic Theory, 9(1), 47-96.

Jun, S.-A. (1996) The phonetics and phonology of Korean prosody: intonational phonology and prosodic structure. New York: Garland Publishing.

Ladd, D. R. (1996) Intonational Phonology. Cambridge: CUP.

Madureira, S. (1999) Entoação e síntese de fala: modelos e parâmetros. In Estudos de Prosódia (E. Scarpa, editor), pp. 53-68. Campinas: Editora da Unicamp.

Martins, A. M. (1994) Os clíticos na história do português. Unpublished Ph.D. dissertation, Universidade de Lisboa.

Moraes, J. A. (1990) Aspects of the Brazilian Portuguese intonation. Unpublished ms., Universidade Federal do Rio de Janeiro.

Moraes, J. A. (1998) Intonation in Brazilian Portuguese. In Intonation Systems: a survey of twenty languages (D. Hirst \& A. Di Cristo, editors), pp. 179-194. Cambridge: Cambridge University Press.

Nespor, M. \& Vogel, I. (1986) Prosodic phonology. Dordrecht: Foris Publications. 
Pierrehumbert, J. (1980) The phonology and phonetics of English intonation. Ph.D. dissertation, M.I.T.

Pierrehumbert, J. \& Beckman, M. (1988) Japanese Tone Structure. Cambridge, Mass.: M. I. T. Press.

Rameh, C. (1962) Contrastive analyses of English and Portuguese intonation. MA dissertation, Georgetown University.

Reis, C. (1984) Aspectos entoacionais do Português de Belo Horizonte. Unpublished MA dissertation, Universidade Federal de Minas Gerais.

Schwindt, L. C. (2000) O prefixo do português brasileiro: análise morfofonológica. Unpublished Ph.D. dissertation, PUCRS.

Schwindt, L. C. (2001) O prefixo no português brasileiro: análise prosódica e lexical, D.E.L.T.A., 17(2), 175-207.

Selkirk, E.O. (1984) Phonology and Sintax: The Relation between Sound and Structure. Cambridge: The M.I.T. Press.

Silva, G. V. (2001) Word Order in Brazilian Portuguese. Berlin/New York: Mouton de Gruyter.

Tavares Silva, C. R. (2004) A Natureza de AGR e suas implicações na ordem VS: um estudo comparativo entre o português brasileiro e o português europeu. Unpublished Ph.D. dissertation, Universidade Federal de Alagoas.

Tenani, L. E. (2002) Domínios prosódicos no Português. Unpublished Ph.D. dissertation, Universidade Estadual de Campinas.

Viana, M. C. (1987) Para a síntese da entoação do Português. Dissertação para acesso à categoria de Investigador Auxiliar, CLUL-INIC (Lisbon).

Vigário, M. (1998) Aspectos da Prosódia do Português Europeu: estruturas com advérbio de exclusão e negação frásica. Braga: CEHUM.

Vigário, M. (2003) The Prosodic Word in European Portuguese. Berlin/New York: Mouton de Gruyter.

\author{
Flaviane Romani Fernandes \\ Universidade Estadual de Campinas \\ Instituto de Estudos da Linguagem \\ Rua Sérgio Buarque de Holanda, ${ }^{\circ} 571$ \\ Caixa Postal 6045 - CEP 13083-970 \\ Campinas - SP - Brasil. \\ flaviane@gmail.com
}

